\title{
Development and validation of a compact on-person storage device (SMHeartCard) for emergency access to acetylsalicylic acid and nitroglycerin
}

\author{
Tyson Le MSc, D. Ian Paterson MD, Neal M. Davies PhD, John R. Mackey MD
}

Abstract

Background: Guidelines recommend that patients with coronary artery disease (CAD) carry and immediately use acetylsalicylic acid (ASA) and sublingually administered nitroglycerin at the onset of chest pain; however, compliance with these recommendations is poor. We designed and tested a compact on-person storage device for these medications.

Methods: We designed an airtight, light-proof and chemically inert holder to carry four 81-mg ASA tablets and three 0.3-mg Nitrostat (nitroglycerin, Pfizer) tablets. After establishing the temperatures ranges in wallets and pockets, we tested nitroglycerin dissolution and release of the stored Nitrostat tablets across a range of relevant temperatures and a variety of tablet enclosure systems.

Results: Microcalorimeter thermal conduction studies as well as dissolution and release testing showed that nitroglycerin tablets were stable at temperatures ranging from $-20^{\circ} \mathrm{C}$ to $60^{\circ} \mathrm{C}$ for 1 week. In testing up to 24 weeks, $0.3-\mathrm{mg}$ Nitrostat tablets enclosed completely in polytetrafluoroethylene (PTFE) performed similarly to those stored in the manufacturer's borosilicate glass packaging across a wide range of temperatures relevant to on-person carriage. Real-world on-person testing for 24 weeks confirmed these results. Non-PTFE enclosures performed poorly.

Interpretation: The PTFE enclosure with a PTFE-coated cap liner maintained long-term performance of 0.3-mg Nitrostat tablets under laboratory and real-world conditions. This storage device is now commercially available as the SMHeartCard to improve compliance and provide immediate access to emergency cardiac medications.

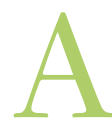
cetylsalicylic acid (ASA) is a potent inhibitor of platelet aggregation and clotting. Nitroglycerin is a vasodilatory drug used to alleviate cardiac chest pain due to inadequate blood supply to the myocardium. The American College of Cardiology Foundation/American Heart Association guideline on management of ST-elevation myocardial infarction recommends ${ }^{1}$ that patients with coronary artery disease (CAD) carry and use both ASA and nitroglycerin at the onset of chest pain. Specifically, patients with known or suspected CAD who experience chest pain should immediately chew and swallow ASA tablets at dosages from $162 \mathrm{mg}$ to $325 \mathrm{mg}$ and take the first of up to 3 doses of a nitroglycerin preparation. ${ }^{1}$ If pain is not relieved, emergency medical services should be activated.

Early administration of ASA and nitroglycerin is beneficial in acute coronary syndromes. Immediate ASA administration lowers mortality from myocardial infarction, with a clear association between the onset of myocardial infarction symptoms and time to ASA administration. ${ }^{2}$ In observational stud- ies, prehospital sublingual administration of nitroglycerin reduced chest pain significantly ${ }^{3}$ and was safe, with the only adverse effect noted being nonclinically significant hypotension $\left(0.7 \%-3.2 \%\right.$ of patients). ${ }^{3,4}$ Prehospital administration of nitroglycerin by emergency response teams is associated with improved survival, ${ }^{5}$ and a Cochrane meta-analysis of inhospital nitrate therapy in acute coronary syndromes showed an improvement in survival when administered within the first 24 hours. ${ }^{6}$

Competing interests: John Mackey holds shares in the SMHeartCard. No other competing interests were declared.

This article has been peer reviewed.

Correspondence to: John Mackey, john.mackey@ albertahealthservices.ca

CMAJ Open 2020. DOI:10.9778/cmajo.20190147 
An audit of a Canadian hospital showed that, among patients presenting with acute coronary syndromes (myocardial infarction or unstable angina), the median time to ASA and nitroglycerin administration was more than 90 minutes after arrival at the emergency department. ${ }^{7}$ About $30 \%$ of people with myocardial infarction do not survive long enough to reach medical care, ${ }^{8}$ and this is more frequent in people who live and work in geographically isolated areas.

Storing ASA requires a low-humidity environment. In contrast, nitroglycerin in its pure form is volatile, reacts with oxygen and degrades with light exposure. Furthermore, nitroglycerin adsorbs to plastics and desiccants used to store and distribute tablets. ${ }^{9}$ Although nitroglycerin sprays are the primary way to carry and administer nitroglycerin in Canada, these are inconvenient and and should not be stored at temperatures lower than $15^{\circ} \mathrm{C} .1^{10}$

The published literature shows poor compliance with onperson carriage of nitroglycerin and ASA. In a prospective Canadian case series conducted in a primary care clinic, 38 consecutive patients with CAD were asked to produce their prescribed nitroglycerin and recommended ASA to a nurse. ${ }^{11}$ Only $7(18 \%)$ of the 38 carried their nitroglycerin; among men, the rate was $12 \%(2 / 17)$. The most frequent explanation for lack of compliance was the inconvenience of carrying nitroglycerin spray. No patient carried ASA. Although self-reported rates of nitroglycerin carriage appear to be higher, ${ }^{12,13}$ self-reported compliance rates generally exceed objectively measured compliance. ${ }^{14,15}$

Improved tablet manufacturing processes now permit long-term storage of nitroglycerin tablets when carried in pant pockets or purses, particularly when headspace (space left at the top of a container to allow for expansion of contents) is minimized. ${ }^{9}$ To improve compliance and provide immediate access to ASA and nitroglycerin, we designed a small, convenient pill holder to fit in wallets, pockets and purses, with clear instructions for its use.

In the current study, we evaluated this holder with a series of nitroglycerin enclosures under a range of laboratory conditions simulating on-person carriage, as well as a 24-week "real-world" evaluation of on-person carriage. We hypothesized that $0.3-\mathrm{mg}$ Nitrostat (nitroglycerin, Pfizer) tablets stored within the medication holder would not differ on in vitro release testing from those stored in the original borosilicate glass packaging at room temperature.

\section{Methods}

We sought to optimize the stability and performance of NitroStat tablets across a variety of physical enclosure systems, under different temperatures, and with and without nitrogen gas packaging. We used thermal degradation testing to evaluate pill stability, and in vitro nitroglycerin release testing simulated sublingual dissolution. The technologist performing the tests was aware whether the pills were being tested under real-world conditions or were control tablets.

\section{Materials}

We purchased 0.3-mg and 0.6-mg Nitrostat tablets from McKesson Canada. We obtained hydrophobic polyvinylidene difluoride Durapore membrane filters (pore size $0.45 \mu \mathrm{m}$, 13-mm membrane) from Millipore Sigma. We purchased high-performance liquid chromatography (HPLC)-grade methanol and octanol from Fischer Scientific. Water used for release tests and HPLC analysis was purified with Elgastat Maxima UF and an Elgastat Option 3B water purifier by ELGA LabWater.

\section{Product design and user testing}

We designed a product made of polypropylene that is small and thin enough to fit in a wallet, holds four 81-mg acetylsalicylic acid tablets, cradles a chemically inert insert to hold 3 nitroglycerin tablets, permits a cap system to completely enclose the tablets in a chemically inert chamber without exposure to air, moisture or light, and has clear directions for medication use. The disassembled system is shown schematically in Figure 1A. The back surface of the holder carries a label with instructions for use and expiration date. The assembled product is shown in Figure 1B and Figure 2. The final design was tested in 5 older cognitively intact people; each was able to read the directions, and understand and manage the device and medications.

\section{Temperature excursions with on-body carriage}

To determine on-body temperature ranges typical for Canadians, we measured minimum and maximum pocket temperatures at 10 -second intervals with a ThermPro TP50 digital LCD indoor hygrometer thermometer humidity meter. Five men and 2 women in Alberta carried this instrument in shirt or pants pockets continuously over 24-hour periods in spring and summer, or fall and winter conditions.

\section{Thermal chemical degradation and high- temperature testing}

Given the possibility of short-term high-temperature exposure, we evaluated the thermal chemical degradation of $0.3-\mathrm{mg}$ Nitrostat tablets at elevated temperatures. Six $0.3-\mathrm{mg}$ Nitrostat tablets were placed inside a stainless steel microcalorimeter ampoule and monitored for thermal degradation with a TAM III thermal activity monitor (TA Instruments) at various conditions $\left(45^{\circ} \mathrm{C}\right.$ with nitrogen gas packaging to determine whether nitrogen would help prevent nitroglycerin degradation, and $45^{\circ} \mathrm{C}, 50^{\circ} \mathrm{C}$ and $60^{\circ} \mathrm{C}$ in atmospheric oxygen) for 1 week. Performance of these pills was then assessed by means of nitroglycerin release testing as described below.

\section{Storage conditions}

We sought to identify the appropriate materials in which to enclose nitroglycerin tablets and to establish whether nitrogen packaging improved stability. As a control for all packaging experiments, Nitrostat tablets were stored at room temperature $\left(21^{\circ} \mathrm{C} \pm 2^{\circ} \mathrm{C}\right)$ in their original borosilicate glass screw-top vial with a plastic-lined metal screw cap. The SMHeartCard case was tested with inserts made from polytetrafluoroethylene (PTFE) (a synthetic fluoropolymer) or borosilicate glass, 


\section{A}

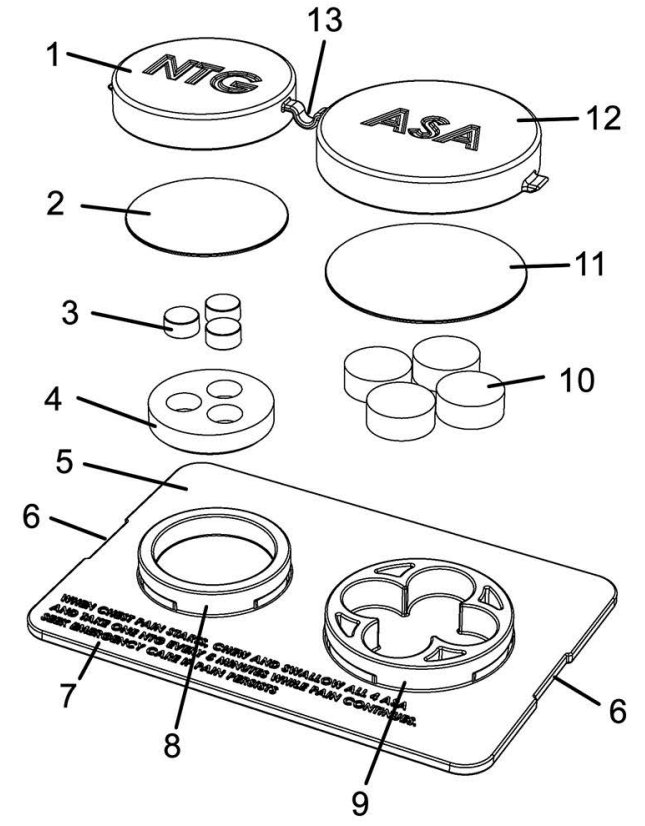

B

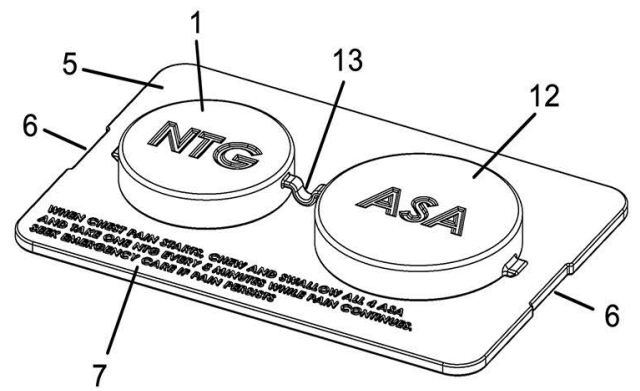

Figure 1: Diagram of the disassembled (A) and assembled (B) cardiac medication holder showing 1) nitroglycerin cap, 2) nitroglycerin polytetrafluoroethylene (PFTE) cap liner, 3) 3 nitroglycerin tablets, 4) PTFE nitroglycerin insert, 5) base 6) grooves, 7) instructions, 8) nitroglycerin insert holder, 9) acetylsalicylic acid (ASA) well, 10) ASA tablets, 11) ASA cap liner, 12) ASA cap and 13) cap bridge.

and with PTFE-coated or polyethylene cap liners. Tablets were also stored with and without nitrogen in PTFE inserts and glass inserts with PTFE-coated cap liners. The tablets were stored for $1,2,4,8,12$ and 24 weeks at $4^{\circ} \mathrm{C}$, room temperature and $35^{\circ} \mathrm{C}$ before release testing to evaluate performance. We performed additional studies at $-20^{\circ} \mathrm{C}$ at 4 weeks.

We performed a confirmatory 24-week "real-world" evaluation with $0.3-\mathrm{mg}$ and $0.6-\mathrm{mg}$ Nitrostat tablets. These tablets were stored in their original borosilicate glass packaging at room temperature (control) or within a SMHeartCard case containing PTFE inserts and cap, and were kept on person within wallets, pockets, backpacks and purses.

\section{In vitro release test}

We used in vitro release testing to simulate Nitrostat exposure to saliva and diffusion into systemic circulation. These studies used Franz glass diffusion cells to determine the cumulative percent drug release. The receptor medium was doubledistilled water, $12-13 \mathrm{~mL}$ in the receptor chamber of each cell. Receptor chambers were maintained at $37.4^{\circ} \mathrm{C} \pm 0.5^{\circ} \mathrm{C}$ by means of a Haake D8 circulating water bath. A magnetic stirring bar (Ikaflon, IKA) was used to stir the receptor medium in each diffusion cell at $600 \mathrm{rpm}$. A $0.45-\mu \mathrm{m}$ synthetic hydrophobic (polyvinylidene difluoride) membrane was briefly soaked in octanol to create a partition replicating a mucosal membrane. The membrane was assembled between the donor and receptor compartments of the Franz cell. A Nitrostat tablet was added on top of the membrane, and $1 \mathrm{~mL}$ of doubledistilled water was added to dissolve the sample. Then, $100-\mu \mathrm{L}$ samples were collected through a sampling port with a needle at 2, 5, 10, 20, 30 and 60 minutes. The same volume withdrawn was replaced with double-distilled water. 

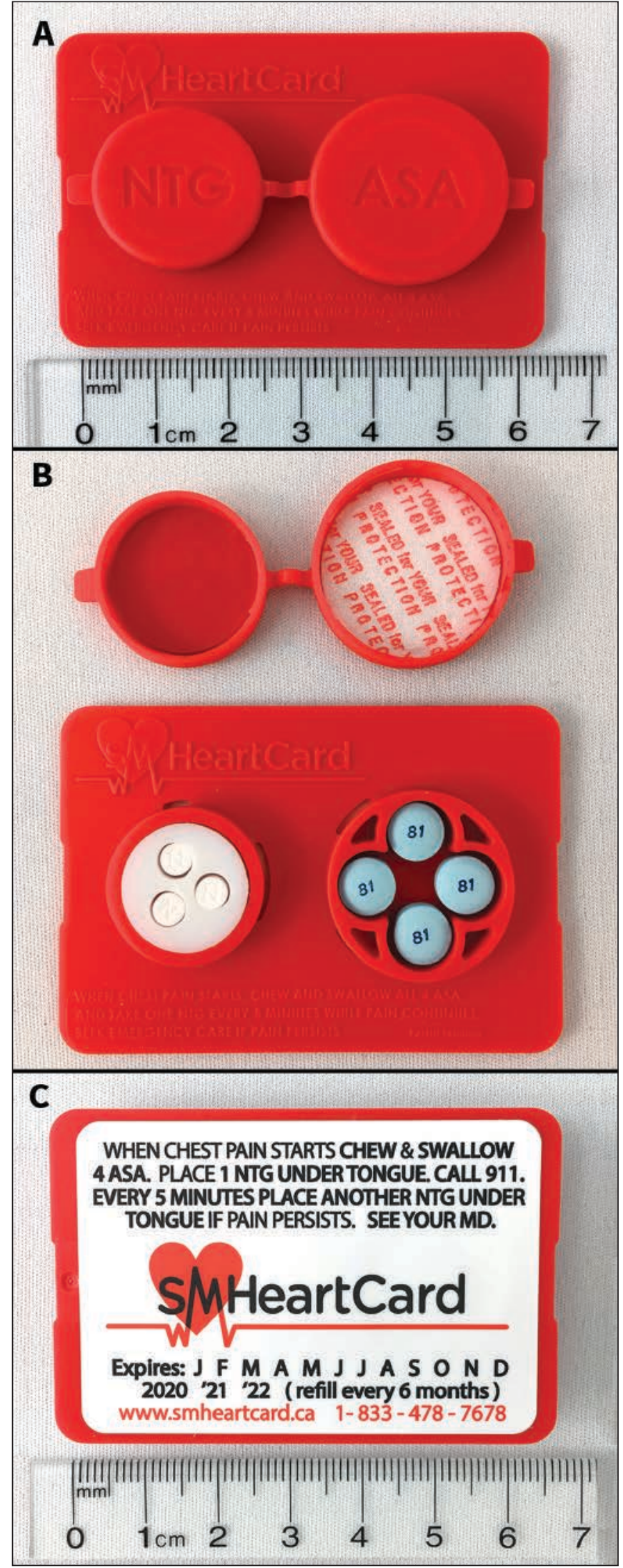

Figure 2: SMHeartCard medication holder capped $(A)$ and uncapped and filled (B), and reverse view (C).
We analyzed the samples using HPLC to assess nitroglycerin release. We adapted HPLC methods from the United States Pharmacopoeia standard ${ }^{16}$ using slight modifications. We carried out the analysis using a system equipped with 2 LC-10ADVP pumps, an SIL-HTc autosampler and an SPD-10AV UV/VIS detector (Shimadzu Corporation). Chromatographic separation was achieved with a Finesse Genesis C18 column $(100 \times 3.00 \mathrm{~mm}, 4 \mu \mathrm{m})($ Chromatographic Specialties) at room temperature. The isocratic mobile phase of methanol in water was $45: 55$ with a flow rate of $0.75 \mathrm{~mL} / \mathrm{min}$. Samples were injected at $50 \mu \mathrm{L}$ with the ultraviolet detector's wavelength set at $210 \mathrm{~nm}$.

\section{Statistical analysis}

We used DDSolver, a Microsoft Excel add-in program, to analyze the release profiles of Nitrostat tablets. As recommended by the US Food and Drug Administration, ${ }^{17}$ we calculated F2 statistics to compare the mean cumulative percent release of nitroglycerin between the control sample and the experimental storage configurations and conditions. F2 is a similarity factor used to measure the similarity between 2 release profiles and takes all points into consideration. F2 values above 50 indicate that 2 release profiles are statistically similar ${ }^{17}$ and therefore meet the US Food and Drug Administration standard of clinically acceptable performance.

\section{Ethics approval}

As the study involved laboratory testing only, ethics approval was not required.

\section{Results}

On-person pocket temperatures ranged from $13.2^{\circ} \mathrm{C}$ to $32.4^{\circ} \mathrm{C}$ (Figure 3 ). We consequently tested various enclosure systems at long-term temperatures ranging from $4^{\circ} \mathrm{C}$ to $35^{\circ} \mathrm{C}$,

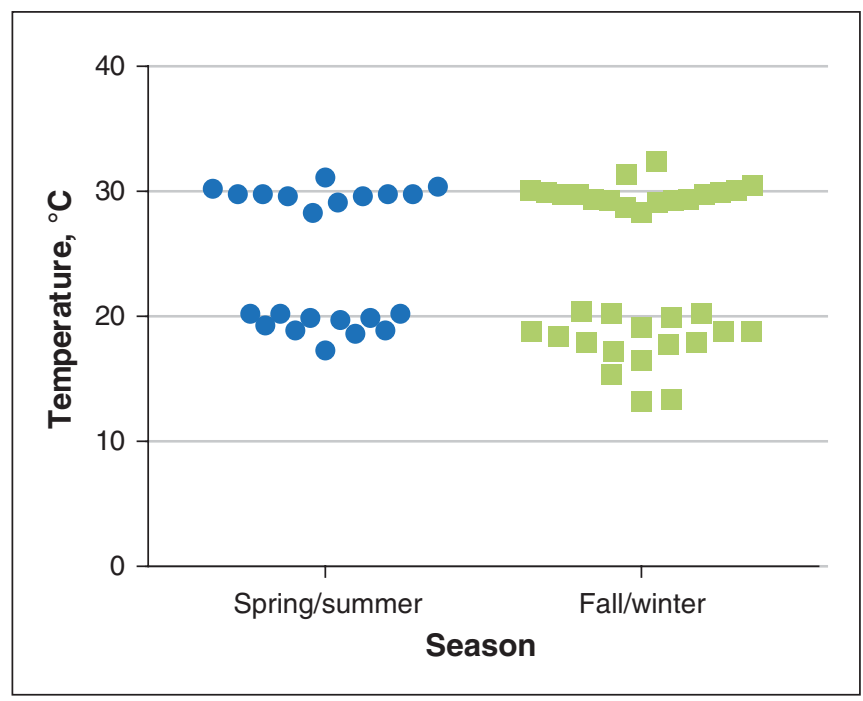

Figure 3: Minimum and maximum 24-hour pocket temperature excursions in spring/summer and fall/winter conditions. Each data point represents a single daily minimum or maximum temperature reading from 1 person. 
and short-term temperature extremes. Nitroglycerin tablets were chemically stable for 1 week at $45^{\circ} \mathrm{C}, 50^{\circ} \mathrm{C}$ and $60^{\circ} \mathrm{C}$; nitrogen packaging did not improve their stability (Figure 4A). One-week exposure to high temperatures $\left(45^{\circ} \mathrm{C}-60^{\circ} \mathrm{C}\right)$ with and without nitrogen packaging did not trigger nitroglycerin degradation or impairment (Figure 4B).

On in vitro nitroglycerin release testing, $0.3-\mathrm{mg}$ Nitrostat tablets stored in PTFE-enclosed conditions (PTFE insert and cap) performed similarly to control samples across a range of temperatures $\left(-20^{\circ} \mathrm{C}, 4^{\circ} \mathrm{C}\right.$, room temperature and $\left.35^{\circ} \mathrm{C}\right)$ (Figure 5, Table 1).

Storage of $0.3-\mathrm{mg}$ tablets with a PTFE insert and cap under real-world conditions for 24 weeks produced release profiles similar to those for the borosilicate glass control, which indicated that these tablets maintained their stability during on-person carriage (Figure 6).

The F2 values for comparison of the similarity in nitroglycerin release profiles between control samples and tablets

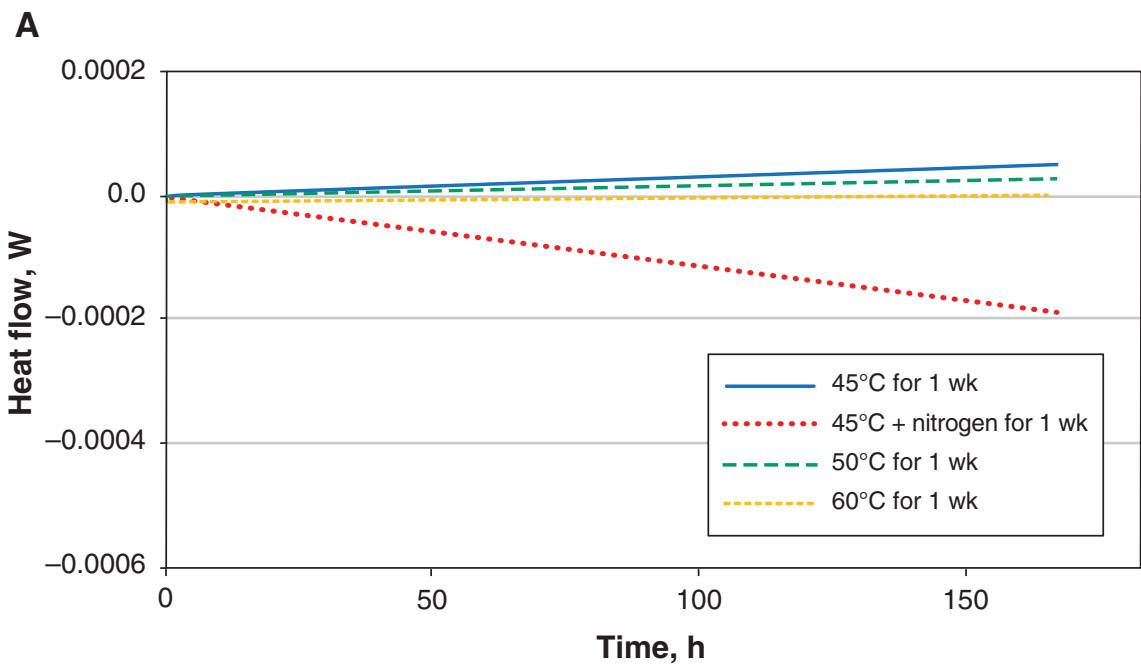

B

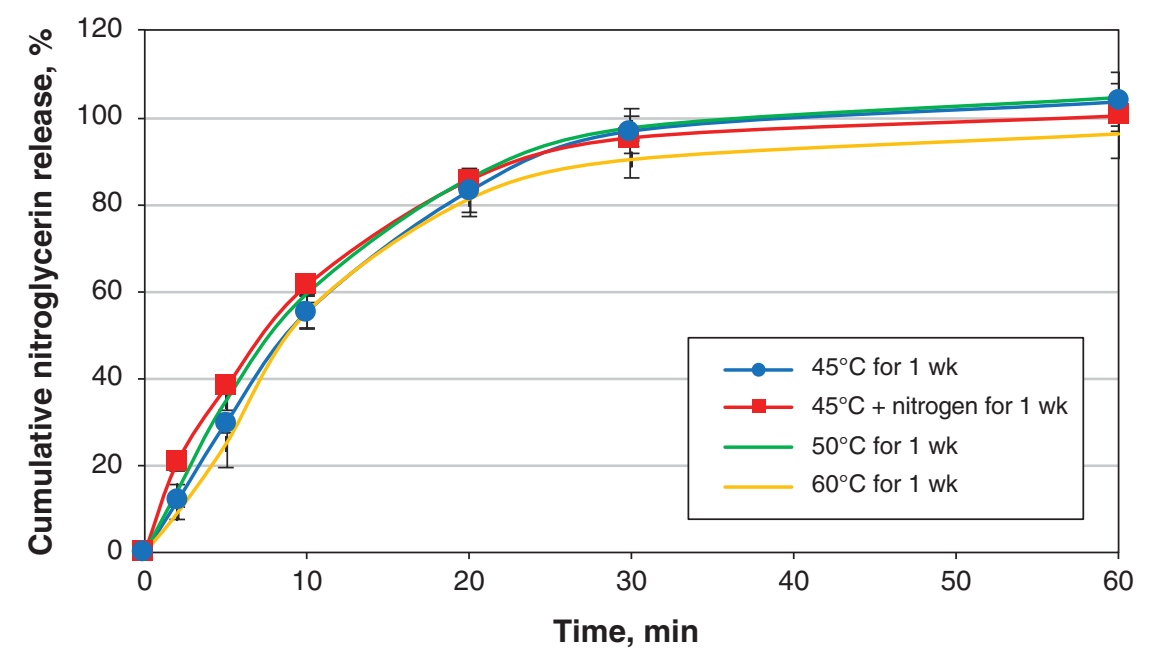

Figure 4: Mean high-temperature $\left(45^{\circ} \mathrm{C}-60^{\circ} \mathrm{C}\right)$ tolerance of six $0.3-\mathrm{mg}$ Nitrostat (nitroglycerin, Pfizer) tablets stored with or without nitrogen packaging for 1 week. (A) Tablets were continuously monitored over 1 week to detect changes in their ability to conduct heat, indicative of thermal degradation. Only small changes in heat flow were observed, even at $60^{\circ} \mathrm{C}$, indicating that the tablets were stable under these conditions. (B) Cumulative nitroglycerin release profiles of tablets stored in a microcalorimeter. Exposure to high temperatures did not trigger nitroglycerin degradation or impairment. Error bars represent standard error of the mean. 


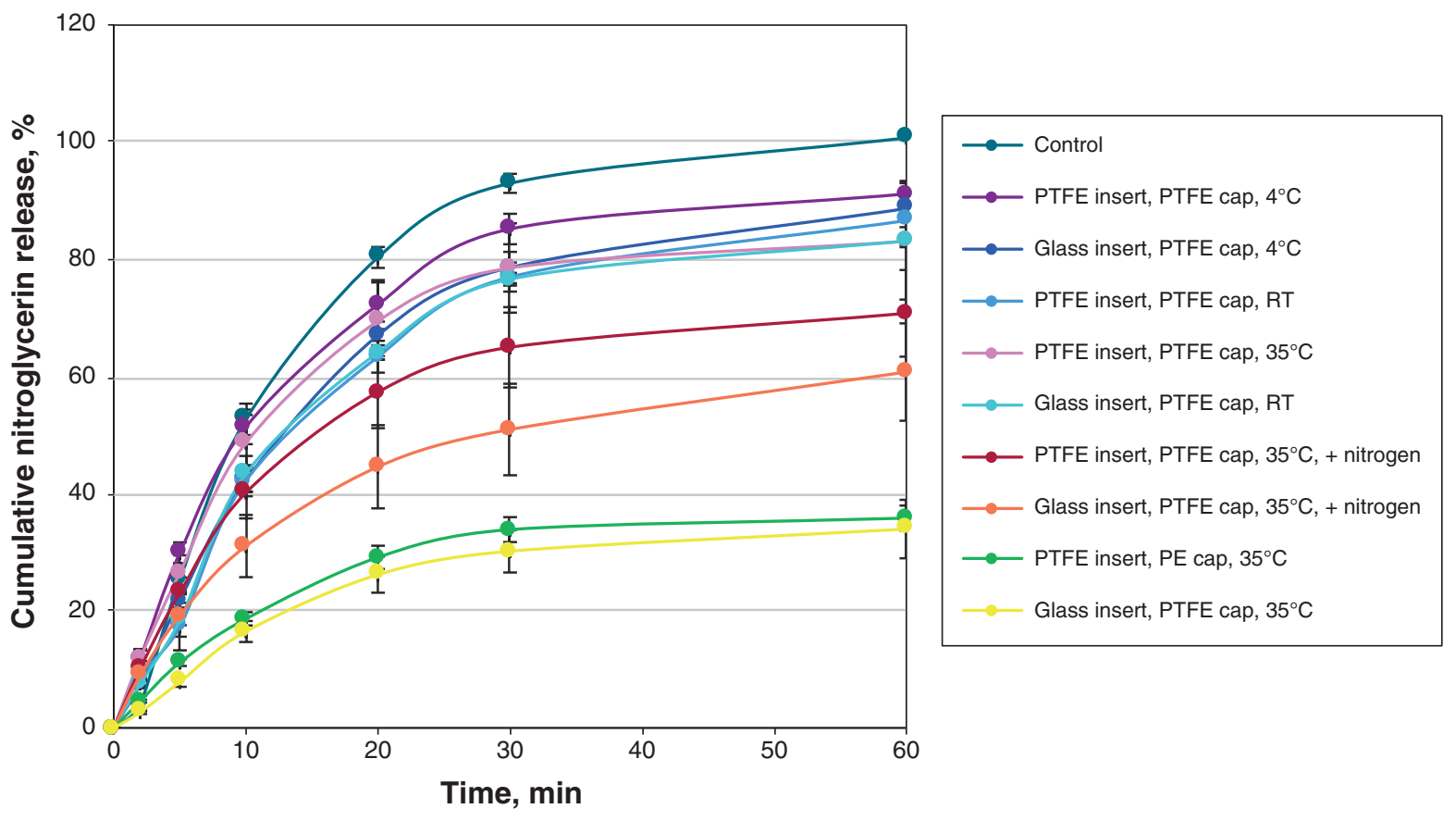

Figure 5: Mean cumulative nitroglycerin release profiles of six 0.3-mg Nitrostat (nitroglycerin, Pfizer) tablets stored in varying holder configurations with or without nitrogen packaging for 24 weeks. Note: PE = polyethylene, PTFE = polytetrafluoroethylene, RT = room temperature. Error bars represent standard error of the mean.

Table 1: Performance of Nitrostat (nitroglycerin, Pfizer) tablets stored in varying packaging configurations $(n=6)$

\begin{tabular}{|c|c|c|c|c|c|c|c|c|c|c|c|c|}
\hline \multirow{3}{*}{$\begin{array}{l}\text { Experimental storage } \\
\text { condition }\end{array}$} & \multicolumn{12}{|c|}{ Week $^{*} \dagger$} \\
\hline & \multicolumn{2}{|c|}{1} & \multicolumn{2}{|c|}{2} & \multicolumn{2}{|c|}{4} & \multicolumn{2}{|c|}{8} & \multicolumn{2}{|c|}{12} & \multicolumn{2}{|c|}{24} \\
\hline & $\mathrm{F} 2$ & S/NS & $\mathrm{F} 2$ & S/NS & $\mathrm{F} 2$ & S/NS & $\mathrm{F} 2$ & S/NS & $\mathrm{F} 2$ & S/NS & $\mathrm{F} 2$ & S/NS \\
\hline \multicolumn{13}{|l|}{$\begin{array}{l}\text { Control: original borosilicate } \\
\text { glass packaging, RT }\end{array}$} \\
\hline PTFE insert, PTFE cap, RT & 64.6 & S & 69.4 & S & 84.6 & S & 86.6 & S & 87.6 & S & 52.4 & $\mathrm{~S}$ \\
\hline $\begin{array}{l}\text { Borosilicate glass insert, } \\
\text { PTFE cap, RT }\end{array}$ & 46.9 & NS & 59.8 & $S$ & 66.1 & $\mathrm{~S}$ & 69.5 & $S$ & 85.8 & $S$ & 58.7 & $S$ \\
\hline PTFE insert, PTFE cap, $4^{\circ} \mathrm{C}$ & 68.5 & $\mathrm{~S}$ & 76.1 & S & 67.4 & S & 68.9 & S & 80.1 & $\mathrm{~S}$ & 58.6 & S \\
\hline $\begin{array}{l}\text { Borosilicate glass insert, } \\
\text { PTFE cap, } 4^{\circ} \mathrm{C}\end{array}$ & 53.2 & $S$ & 59.6 & $S$ & 75.6 & $S$ & 85.0 & $S$ & 73.5 & $S$ & 62.9 & $S$ \\
\hline PTFE insert, PTFE cap, $35^{\circ} \mathrm{C}$ & 62.3 & S & 78.2 & S & 71.1 & S & 95.1 & S & 64.8 & S & 61.8 & $\mathrm{~S}$ \\
\hline $\begin{array}{l}\text { Borosilicate glass insert, } \\
\text { PTFE cap, } 35^{\circ} \mathrm{C}\end{array}$ & 46.7 & NS & 71.4 & $\mathrm{~S}$ & 64.1 & $S$ & 82.2 & $S$ & 58.1 & $S$ & 26.4 & NS \\
\hline PTFE insert, PE cap, $35^{\circ} \mathrm{C}$ & 77.4 & S & 82.3 & $S$ & 44.3 & NS & 46.3 & NS & 45.0 & NS & 30.2 & NS \\
\hline $\begin{array}{l}\text { PTFE insert, PTFE cap, } \\
35^{\circ} \mathrm{C}, \mathrm{N}_{2} \text { packaging }\end{array}$ & 58.8 & $S$ & 78.7 & $\mathrm{~S}$ & 65.1 & $S$ & 75.7 & $S$ & 84.2 & $S$ & 37.1 & NS \\
\hline $\begin{array}{l}\text { Borosilicate glass insert, PTFE } \\
\text { cap, } 35^{\circ} \mathrm{C}, \mathrm{N}_{2} \text { packaging }\end{array}$ & 55.0 & $S$ & 61.2 & $S$ & 75.8 & $S$ & 62.0 & S & 77.1 & $\mathrm{~S}$ & 31.1 & NS \\
\hline PTFE insert, PTFE cap, $-20^{\circ} \mathrm{C}$ & - & - & - & - & 60.1 & S & - & - & - & - & - & - \\
\hline $\begin{array}{l}\text { PTFE insert, PTFE cap, } \\
\text { 0.3-mg, RWC }\end{array}$ & - & - & - & - & - & - & - & - & - & - & 56.0 & $S$ \\
\hline $\begin{array}{l}\text { PTFE insert, PTFE cap, } \\
\text { 0.6-mg, RWC }\end{array}$ & - & - & - & - & - & - & - & - & - & - & 49.9 & NS \\
\hline
\end{tabular}




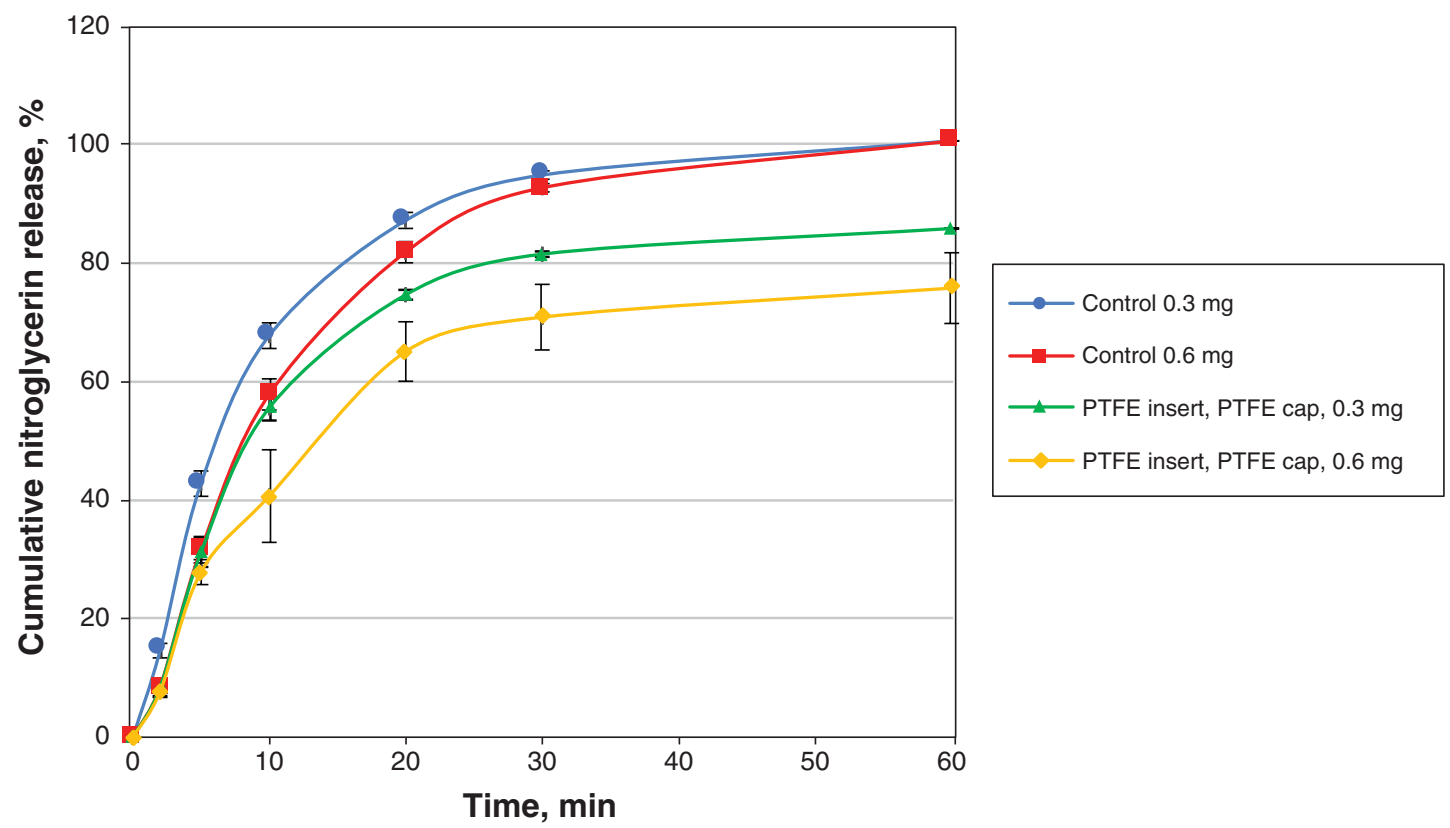

Figure 6: Mean nitroglycerin release profiles of six 0.3-mg and six 0.6-mg Nitrostat (nitroglycerin, Pfizer) tablets stored at room temperature for 24 weeks in original borosilicate glass packaging (controls) and enclosed with polytetrafluoroethylene (PTFE) under real-world conditions for 24 weeks. Error bars represent standard error of the mean.

stored under the test conditions described for all experiments are given in Table 1 . Taken together, these results showed that $0.3-\mathrm{mg}$ Nitrostat tablets were stable across a range of temperatures $\left(-20^{\circ} \mathrm{C}\right.$ to $\left.35^{\circ} \mathrm{C}\right)$ when enclosed in PTFE for up to 24 weeks.

Storage conditions that did not perform similarly to the control included a borosilicate glass insert and PTFE cap; PTFE insert and polyethylene cap; nitrogen packaging (PTFE insert, PTFE cap and glass insert, PTFE cap) at $35^{\circ} \mathrm{C}$; and 0.6-mg Nitrostat tablets in PTFE insert with PTFE cap under real-world conditions (Figure 5, Table 1).

Representative HPLC traces of nitroglycerin peaks obtained after Nitrostat tablet storage can be found in Appendix 1 (available at www.cmajopen.ca/content/8/1/E75/suppl/ DC1).

Based on the results of the above tests, the configuration chosen for the commercial SMHeartCard case was a PTFE cap liner and PTFE insert to enclose $0.3-\mathrm{mg}$ NitroStat tablets, without nitrogen packaging.

\section{Interpretation}

We evaluated several configurations and conditions to optimize the stability of nitroglycerin tablets for longterm on-person carriage. Among the experimental permutations, we found that tightly enclosed $0.3-\mathrm{mg}$ Nitrostat tablets in a PTFE insert covered with a PTFE-coated cap liner maintained long-term performance properties for 24 weeks under both laboratory and real-world conditions. Nitrogen packaging provided no benefit. The com- plete PTFE enclosure performed as well as storage in standard borosilicate glass vials.

Our finding that the SMHeartCard holder is an effective storage device to provide immediate access to emergency cardiac medications for 24 weeks suggests that the product has the potential to reduce myocardial infarction mortality by improving access and timeliness of treatment.

The results are of potential importance to 3 groups. The first group is the population with established CAD, whose compliance with carrying ASA and standard nitroglycerin spray formulations is poor. ${ }^{11}$ The second group comprises people with risk factors for myocardial infarction but without a previous cardiac ischemic event. Canadians have a high prevalence of risk factors for CAD,${ }^{18}$ and treatment of modifiable risk factors reduces, but does not eliminate, the risk of myocardial infarction. In addition, although people with cardiovascular risk factors are sometimes advised to take daily low-dose ASA as prophylaxis, new evidence suggests that, for older people, the risks of daily ASA use outweigh the benefits. ${ }^{19}$ Finally, first responders and those trained in first aid may wish to carry the SMHeartCard to provide immediate treatment to people with heart attack symptoms.

\section{Limitations}

Our study has several limitations. We have not tested the SMHeartCard for periods exceeding the manufacturer's recommended 6 months and thus recommend replacement of NitroStat pills every 6 months. The laboratory studies were conducted by qualified technical staff, but the technicians 
were not blinded to the experimental storage conditions. To demonstrate improved compliance with SMHeartCard carriage compared to sublingually administered nitroglycerin spray preparations, a formal prospective clinical trial will be required.

\section{Conclusion}

We designed and validated a medication storage device to permit on-person carriage and immediate treatment of symptoms of myocardial infarction and angina. Given that time to initial treatment is an important determinant of survival in myocardial infarction and that a substantial proportion of myocardial infarctions are fatal before the patient reaches the hospital, this device has the potential to improve outcomes in people with established and previously undiagnosed CAD.

Note: This product is patented (CA180764S) and trademarked as SMHeartCard, and is now marketed in Canada (www.smheartcard.ca) for on-person carriage of ASA and 0.3-mg Nitrostat tablets.

\section{References}

1. O'Gara PT, Kushner FG, Ascheim DD, et al. 2013 ACCF/AHA guideline for the management of ST-elevation myocardial infarction: a report of the American College of Cardiology Foundation/American Heart Association Task Force on Practice Guidelines. 7 Am Coll Cardiol 2013;61:e78-140.

2. Randomised trial of intravenous streptokinase, oral aspirin, both, or neither among 17,187 cases of suspected acute myocardial infarction: ISIS-2. ISIS-2 (Second International Study of Infarct Survival) Collaborative Group. Lancet 1988;2:349-60.

3. Clemency BM, Thompson JJ, Tundo GN, et al. Prehospital high-dose sublingual nitroglycerin rarely causes hypotension. Prehosp Disaster Med 2013;28: 477-81.

4. Engelberg S, Singer AJ, Moldashel J, et al. Effects of prehospital nitroglycerin on hemodynamics and chest pain intensity. Prehosp Emerg Care 2000;4:290-3.

5. Strandmark R, Herlitz J, Axelsson C, et al. Determinants of pre-hospital pharmacological intervention and its association with outcome in acute myocardial infarction. Scand 7 Trauma Resusc Emerg Med 2015;23:105.

6. Perez MI, Musini VM, Wright JM. Effect of early treatment with antihypertensive drugs on short and long-term mortality in patients with an acute cardiovascular event. Cochrane Database Syst Rev 2009;(4):CD006743.

7. Dufresne F, Blouin D, Xue X, et al. Underutilization of acetylsalicylic acid for acute coronary syndromes in the emergency department. CFEM 2004;6:333-6.

8. Dudas K, Lappas G, Stewart S, et al. Trends in out-of-hospital deaths due to coronary heart disease in Sweden (1991 to 2006). Circulation 2011;123:46-52.

9. Nawarskas JJ, Koury J, Lauber DA, et al. Open-label study of the stability of sublingual nitroglycerin tablets in simulated real-life conditions. Am 7 Cardiol 2018;122:2151-6.
10. Product monograph: Apo-Nitroglycerin [Internet] (revised Sept. 21, 2016). Toronto: Apotex Inc.; 2016. Available: https://pdf.hres.ca/dpd_pm/00036567. PDF (accessed 2020 Jan. 28).

11. Horsman C, Frederick T. Poor compliance with carrying nitroglycerin and aspirin in patients with coronary artery disease. Can 7 Cardiol 2018;34:945.e1.

12. Sherrard H, Duchesne L, Wells G, et al. Using interactive voice response to improve disease management and compliance with acute coronary syndrome best practice guidelines: a randomized controlled trial. Can 7 Cardiovasc Nurs 2015;25:10-5.

13. Kimble LP, Kunik CL. Knowledge and use of sublingual nitroglycerin and cardiac-related quality of life in patients with chronic stable angina. 7 Pain Symptom Manage 2000;19:109-17.

14. Daniels T, Goodacre L, Sutton C, et al. Accurate assessment of adherence: self-report and clinician report vs electronic monitoring of nebulizers. Chest 2011;140:425-32.

15. Grymonpre RE, Didur CD, Montgomery PR, et al. Pill count, self-report, and pharmacy claims data to measure medication adherence in the elderly. Ann Pharmacother 1998;32:749-54.

16. United States Pharmacopeia - national formulary. 39th ed. Rockville (MD): United States Pharmacopeial Convention; 2016:1076.

17. Shah RB, Khan MA. The science and regulatory perspectives of emerging controlled release dosage forms. In: Wen H, Park K, editors. Oral controlled release formulation design and drug delivery: theory to practice. Hoboken (NJ): John Wiley \& Sons; 2010:337-49.

18. Tanuseputro P, Manuel DG, Leung M, et al.; Canadian Cardiovascular Outcomes Research Team. Risk factors for cardiovascular disease in Canada. Can $\mathcal{f}$ Cardiol 2003;19:1249-59.

19. McNeil JJ, Woods RL, Nelson MR, et al.; ASPREE Investigator Group. Effect of aspirin on disability-free survival in the healthy elderly. $N$ Engl 7 Med 2018;379:1499-508.

Affiliations: Faculties of Pharmacy and Pharmaceutical Sciences (Le, Davies) and of Medicine and Dentistry (Paterson), University of Alberta; Alberta Health Services (Mackey), Cross Cancer Institute, Edmonton, Alta.

Contributors: John Mackey led the project, designed and conducted some of the experiments and drafted the manuscript. Neal Davies designed the performance-testing experiments and interpreted the data. Tyson Le performed the laboratory studies and collected and analyzed the data. Ian Paterson reviewed the manuscript critically for important intellectual content. All of the authors approved the final version to be published and agreed to be accountable for all aspects of the work.

Funding: Product prototypes and supplies for this study were provided by SMHeartCard.

Acknowledgements: The authors thank James Stewart for input on the SMHeartCard design, Carol Paul and Suzette Cabral-Mackey for logistical support, Dr. Catherine Horsman for feedback on product design, Edith Pituskin for advice on knowledge translation, Darrin Berlin, Claudia Johnston and Murtaza Hassanali for advice on the needs of Canadian pharmacists and Deanna Hockley for publication coordination.

Supplemental information: Copies of the data are available from the authors on request and with the permission of SMHeartCard. For reviewer comments and the original submission of this manuscript, please see www.cmajopen.ca/content/8/1/E75/suppl/DC1. 